JIOM Nepal. Volume 41 Number 3. December 2019, page 13-16.

\title{
Screening of Kidney Disease in Asymptomatic Female College Students by Urine Dipstick Method
}

\section{Santosh Chhetri, Dibya S Shah}

Department of Nephrology, Maharajgunj Medical Campus, Tribhuvan University Teaching Hospital, Maharajgunj, Kathmandu, Nepal

\section{Corresponding author:}

\section{Santosh Chhetri, MBBS, MD}

Department of Nephrology, Maharajgunj Medical Campus, Tribhuvan University Teaching Hospital, Maharajgunj, Kathmandu, Nepal

Email: santoskpr@gmail.com

Submitted : August 7, 2019

Accepted : September 10, 2019

\begin{abstract}
Introduction

Urine examination by urine dipstick method is a useful tool to identify asymptomatic individual for kidney disease. A urine dipstick analysis was conducted on world kidney day to determine the urine abnormalities among asymptomatic female college students.
\end{abstract}

\section{Methods}

A cross-sectional study was carried out in a government female college in Kathmandu Nepal. Three hundred asymptomatic female students participated in this study. Fresh midstream urine samples were obtained and tested by urine dipstick method. Random Blood glucose was monitored with glucometer. Blood pressure was measured by manual sphynomanometer.

\section{Results}

The mean age of the female students was $22.62 \pm 2.686$ years. Fifteen participants (5\%) were found positive for proteinuria and only $1 \%$ of participants had glycosuria. The systolic blood pressure of $>120 \mathrm{~mm} \mathrm{Hg}$ was present in $14 \%$ of participants while $5 \%$ of participants had diastolic blood pressure of $>90 \mathrm{~mm} \mathrm{Hg}$. Participants who were found to have urinary proteinuria detected had both systolic and diastolic blood pressure increased. Only $8 \%$ of the participants had random blood sugar of $>140 \mathrm{mg} / \mathrm{dl}$.

\section{Conclusion}

Urinary abnormalities like proteinuria and glycosuria in asymptomatic female students has significant prevalence. Systemic prehypertension and hypertension has alarming rates among adolescents. Hence, screening for blood pressure and early detection of renal disorders will lead to effective interventions and possibly reduce the burden of renal diseases.

Keywords: Female adolescents, glycosuria, proteinuria, screening, urinalysis

\section{INTRODUCTION}

ndividuals with early kidney damage have no symptoms and the majority of them are undiagnosed, even in developed countries. ${ }^{1,2}$ Chronic glomerulitis is an important cause of chronic kidney disease in developing countries like Nepal and most primary chronic glomerulitis manifest as asymptomatic proteinuria and or hematuria. $3,4,5$

Analysis of the urine by dipstick method is a simple, easy, inexpensive and non-invasive laboratory test which gives instant result. However, the information it gives can be valuable and remains to be the cornerstone in the assessment of the renal dysfunction and is rightly considered as poor man's renal biopsy. ${ }^{6}$

In different countries in the world, screening programs in healthy adults are performed for detection of kidney disease. Asymptomatic persistent proteinuria may be the first manifestation 
of significant renal and systemic diseases like IgA nephropathy, membranous nephropathy, membranoproliferative glomerulonephritis and so on. ${ }^{7.8}$ Persistent proteinuria and hypertension are key factors that accelerates renal function deterioration in individuals with renal disease.

Mass screening by urinalysis helps to determine the prevalence of renal disease and to improve the outcome in the population. 9,10

Existing data on screening focus on those aged over 35 years. ${ }^{11}$ There are few data regarding the value of screening in younger populations. ${ }^{12,13}$

A cross-sectional study was conducted on the occasion of World Kidney Day 2018 to examine the presence of abnormal urinary findings by urine dipstick test. Blood pressure was measured manually and random blood glucose level was measured by glucometer.

\section{METHODS}

On World Kidney Day 2018, Department of Nephrology and Transplant Medicine, Tribhuvan University Teaching Hospital (TUTH) set up screening station at Padmakanya Campus, Putalisadak Kathmandu. The team consisted of nephrologists, nephrology residents, medicine residents, medical students and nurses.

Apparently healthy female students were screened for urinary abnormalities by urine dipstick method. The participants did not have clinical evidence of kidney or systemic disease.

A preformed proforma was used by screening team to collect data. All members of screening team were instructed on how to take blood pressure, random blood glucose by glucometer and how to read urine dipstick result prior to start of screening program.

Age of the participants was recorded. Systolic and diastolic blood pressure were recorded with manual sphynomanometer. Random blood glucose level were obtained with glucometer and recorded.

The participants were instructed individually how to collect mid-stream urine for examination specifically. The freshly collected urine samples were examined with urine dipsticks for proteinuria and glycosuria. The results were obtained by visual comparison of the test strip with colour chart provided on the bottle label.

At the end, students were informed about their findings in urinalysis, blood pressure measurement and random glucose by glucometer. Those with abnormalities were advised to follow up in the medical institutions for further evaluation.

Statistical analysis was performed by using SPSS Statistics version 25.0. Qualitative data were expressed as numbers and percentages. Comparison between data were performed by using the chi square test. P value of less than 0.05 was considered statistically significant.

\section{RESULTS}

A total of 300 students were enrolled in the study for screening urinalysis. The age of participants was $18-29$ years with mean age of $22.6 \pm 2.6$ years.

Majority of the participants (86\%) had systolic blood pressure of $<120 \mathrm{~mm}$ of $\mathrm{Hg}$. Eight percent (24) of the participants had systolic blood pressure of $120-130 \mathrm{~mm}$ of $\mathrm{Hg}$ whereas the systolic blood pressure of $>130 \mathrm{~mm} \mathrm{Hg}$ was present in about $6 \%$ participants.

Only $1 \%$ of participants had diastolic blood pressure of $>90 \mathrm{~mm} \mathrm{Hg}$. Majority of the participants (95\%) had diastolic blood pressure of $<80 \mathrm{~mm}$ of $\mathrm{Hg}$.

Among 300 participants, 15 (5\%) of them had proteinuria detected by urine dipstick test.

Table 1. Comparison of proteinuria and blood pressure

\begin{tabular}{|c|c|c|c|c|c|c|}
\hline \multirow{2}{*}{ Blood pressure } & \multicolumn{2}{|c|}{ Proteinuria } & \multirow{2}{*}{$\begin{array}{c}\text { Total } \\
\text { subjects }\end{array}$} & \multirow{2}{*}{$\begin{array}{l}\text { Pearson } \chi^{2} \\
\text { value }\end{array}$} & \multirow{2}{*}{ Df } & \multirow{2}{*}{$\mathrm{p}$-value } \\
\hline & Present & Absent & & & & \\
\hline \multicolumn{7}{|l|}{ SBP } \\
\hline$<120$ & 7 & 252 & 259 & 22.43 & 2 & $<0.005$ \\
\hline $120-130$ & 4 & 20 & 24 & & & \\
\hline$>130$ & 4 & 13 & 17 & & & \\
\hline Total & 15 & 285 & 300 & & & \\
\hline \multicolumn{7}{|l|}{ DBP } \\
\hline$<80$ & 12 & 273 & 285 & 8.883 & 2 & 0.012 \\
\hline $80-90$ & 2 & 10 & 12 & & & \\
\hline$>90$ & 1 & 2 & 3 & & & \\
\hline Total & 15 & 285 & 300 & & & \\
\hline
\end{tabular}


Only $1 \%$ of the participants had positive test for glucose in the urine dipstick test.

The average random blood sugar monitored by glucometer among the participants was $106.6 \pm 25.6 \mathrm{mg} / \mathrm{dl}$ with the range of $59-202 \mathrm{mg} /$ dl. Only $8 \%$ of the participants had random blood sugar of $>140 \mathrm{mg} / \mathrm{dl}$.

Individuals with proteinuria were found to have elevated systolic blood pressure which was statistically significant as depicted in Table 1. Diastolic blood pressure was found increased among participants with proteinuria which was statistically significant as depicted in Table 1.

\section{DISCUSSION}

In developing countries like Nepal, a major problem in nephrology service is how to define strategies that can detect early urinary abnormalities in asymptomatic individuals who are at risk of developing chronic kidney disease later in life, hence a screening program is recommended in this regards. ${ }^{14}$

In the current study, the prevalence of asymptomatic urinary abnormalities as proteinuria in female college students was 5\%. Our findings are in contrast to previous studies by Bakr et $\mathrm{al}^{15}$ that found only $1.3 \%$ of the sample have abnormalities and Bolivian study by Plata et $a^{16}$ that reported urinary abnormalities in $30.3 \%$. This huge difference in the prevalence of urinary abnormalities may be because these studies evaluated the presence of hematuria and leucocyturia as well, which was not in our study.

The studies from different other countries showed lower prevalence of asymptomatic urinary abnormalities in school children such as $0.62 \%$ in Japan20, 0.3\% in Taiwan ${ }^{17}, 1.9 \%$ in Malaysia ${ }^{18}$ and $5.25 \%$ in Nigeria. ${ }^{19}$

Studies suggest the increase in prevalence with increasing age. Accordingly, some countries like Japan, introduced an annual urinalysis screening program for every working adults in 1972 and for every resident older than 40 years of age in 1982. ${ }^{20,21}$

The prevalence of proteinuria in our study was $5 \%$. This prevalence is higher than that reported from Tokyo ${ }^{20}$ and Lebanon ${ }^{22}(0.08 \%$ and $0.1 \%$ respectively). The prevalence of proteinuria in studies from Egypt ${ }^{23}$ was $2.13 \%$, Northern Iran ${ }^{24}$ was $1.6 \%$, Nigeria ${ }^{19}$ was $3.5 \%$ and from India ${ }^{25}$ was $2.6 \%$.

The levels of proteinuria are one of the strongest predictors of renal function deterioration. ${ }^{26}$ Asymptomatic proteinuria warrants further work- up to detect and prevent chronic kidney disease. ${ }^{27}$

Different studies have shown females have significantly more proteinuria than males ${ }^{9,28}$ but opposite finding was shown by Lin et al. ${ }^{29}$

In our study, $14 \%$ of the participants had systolic blood pressure $>120 \mathrm{~mm}$ of $\mathrm{Hg}$ and $5 \%$ of the participants had diastolic blood pressure $>80 \mathrm{~mm}$ of $\mathrm{Hg}$. The systolic blood pressure of $>130$ was present in $6 \%$ of participants and $1 \%$ of them had diastolic blood pressure of $>90 \mathrm{~mm}$ of $\mathrm{Hg}$. A variety of studies conducted in different parts of the world revealed a vast range in the prevalence of hypertension in children showing as high as $22 \%$ to as low as $0.6 \% .{ }^{30}$ Chadha, et al. reported about $11.7 \%$ prevalence in school children of Delhi while Anand and Tandon, et al. reported $0.4 \%$ prevalence of hypertension in the age group of 5-17 years. ${ }^{31}$ Prabhajot, et al. found the prevalence of hypertension in Amritsar, Punjab to be $8.3 \%$ and $6.52 \%$ among boys and girls respectively. ${ }^{32}$

\section{CONCLUSION}

The present study concluded that urine screening with dipstick analysis is a simple, feasible and cost effective method for screening of urine abnormalities in asymptomatic female adolescents. Proteinuria and prehypertension was detected in significant participants. Early medical workup for detected urinary abnormalities and thereby medical intervention may lead to prevention or retard progression of the disease. We suggest, urine routine examination and BP monitoring should be a part of screening student at college entry in Nepal and further work up should be offered to identify the underlying pathology when needed.

\section{CONFLICT OF INTEREST}

None declared.

\section{REFERENCES}

1. Coresh J, Astor BC, Greene T, Eknoyan G, et al. Prevalence of chronic kidney disease and decreased kidney function in the adult US population: Third National Health and Nutrition Examination Survey. Am J Kidney Dis 2003; 41:112.

2. Schieppati A, Remuzzi G. Chronic renal diseases as a public health problem: epidemiology, social, and economic implications. Kidney Int Suppl 2005; 98:S7-10.

3. Tiebosch AT, Wolters J, Frederik PF, et al. Epidemiology of idiopathic glomerular disease: a prospective study. Kidney Int 1987; 32:112-6.

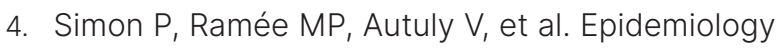
of primary glomerular diseases in a French region. 
Variations according to period and age. Kidney Int 1994; 46:1192-8.

5. Cameron JS. Proteinuria and progression in human glomerular diseases. Am J Nephrol 1990; 10 Suppl 1:81-7.

6. Fraser CG, Smith BC, Peake MJ. Effectiveness of an outpatient urine screening program. Clin Chem 1977; 23:2216-8.

7. Woolhandler S, Pels RJ, Bor DH, Himmelstein DU, Lawrence RS. Dipstick urinalysis screening of asymptomatic adults for urinary tract disorders. I. Hematuria and proteinuria. JAMA 1989; 262:12149.

8. Jafar $\mathrm{TH}$, Stark $\mathrm{PC}$, Schmid $\mathrm{CH}$, et al. Proteinuria as a modifiable risk factor for the progression of non-diabetic renal disease. Kidney Int 2001; 60:1131-40.

9. Park YH, Choi JY, Chung HS, et al. Hematuria and proteinuria in a mass school urine screening test. Pediatr Nephrol 2005; 20:1126-30.

10. Froom P, Ribak J, Benbassat J. Significance of microhaematuria in young adults. Br Med J (Clin Res Ed) $1984 ;$ 288:20-2.

11. Britton JP, Dowell AC, Whelan P, Harris CM. A community study of bladder cancer screening by the detection of occult urinary bleeding. J Urol1992; 148:788-790.

12. Kawamura T, Ohta T, Ohno $Y$ et al. Significance of urinalysis for subsequent kidney and urinary tract disorders in mass screening of adults. Intern Med1995; 34:475-480.

13. Levitt JI. The prognostic significance of proteinuria in young college students. Ann Intern Med1967; 66:685-696.

14. Hogg RJ, Furth S, Lemley KV, et al. National Kidney Foundation's Kidney Disease Outcomes Quality Initiative clinical practice guidelines for chronic kidney disease in children and adolescents: evaluation, classification, and stratification. Pediatrics 2003; 111(6 Pt 1): 1416-21.

15. Bakr A, Sarhan A, Hammad A, et al. Asymptomatic urinary abnormalities among primary school children in Egypt. World J Pediatr 2007; 3:214-7.

16. Plata R, Silva $C$, Yahuita J, Perez $L$, et al. The first clinical and epidemiological programme on renal disease in Bolivia: a model for prevention and early diagnosis of renal diseases in the developing countries. Nephrol Dial Transplant 1998;13:30346.

17. Park YH, Choi JY, Chung HS, et al. Hematuria and proteinuria in a mass school urine screening test. Pediatr Nephrol 2005;20:1126-30.

18. Zainal D, Baba A, Mustaffa BE. Screening proteinuria and hematuria in Malaysian children. Southeast Asian J Trop Med Public Health 1995;26:785-8.

19. Akor F, Okolo S, Agaba E, Okolo A. Urine examination findings in apparently healthy new school entrants in Jos, Nigeria. S Afr J Child Health 2009;3:60-3.

20. Murakami $M$, Yamamoto $H$, Ueda $Y$, et al. Urinary screening of elementary and junior high-school children over a 13year period in Tokyo. Pediatr Nephrol 1991; 5:50-3.

21. Yamagata K, Iseki K, Nitta K, et al. Chronic kidney disease perspectives in Japan and the importance of urinalysis screening. Clin Exp Nephrol 2008;12:1-8.

22. Hajar F, Taleb M, Aoun B, Shatila A. Dipstick urine analysis screening among asymptomatic school children. N Am J Med Sci 2011;3:17984.

23. El-Shafie AM, El-Nemr FM, Bahbah MH, et al. The role of urine screening (In School Children of Menoufiya Governorate) in early detection of renal disorders. J Am Sci 2014;10:143-150.

24. Badeli $H$, Heidarzadeh $A$, Ahmadian M. Prevalence of hematuria and proteinuria in healthy 4 to 6 year old children in daycare centers of Rasht (Northern Iran). Iran J Pediatr 2009; 19:169-72.

25. Sharma AK, Gupta R, Agarwal VS, et al. Prevalence of proteinuria in school children. Indian J Nephrol 1998;8:96-737.

26. Iseki K, Ikemiya Y, Iseki C, Takishita S. Proteinuria and the risk of developing endstage renal disease. Kidney Int 2003; 63: 146874.

27. Hanif R, Ally SH, Jalal-ud-Din Khan K. Effectiveness of routine urine analysis of patient attending rural health centers in Abbottabad. J Ayub Med Coll Abbottabad 2006; 18: 63-4.

28. Oviasu E, Oviasu SV. Urinary abnormalities in asymptomatic adolescent Nigerians. West Afr J Med 1994; 13:152-5.

29. Lin CY, Hsieh CC, Chen WP, et al. The underlying disease and follow up in Taiwanese children screened by urinalysis. Pediatr Nephrol 2001; 16:232-7.

30. Task Force on Blood Pressure Control in Children (1996) Report of the second Task Force on Blood Pressure Control in Children. Pediatrics 79: 1-25.

31. Chadha SL, Tandon R, Shekhawat S, Gopinath $N$. An epidemiological study of blood pressure in school children (5-14 years) in Delhi. Indian Heart J 1999; 51(2): 178-182.

32. Prabhjot A, Kaur N, Kumari K, Sidhu. Variation in blood pressure among school children of Amritsar (Punjab). Anthropologist 2005; 7(3): 201-204. 